\title{
Dynamic Recrystallization and Its Effect on Superior Plasticity of Cold-Rolled Bioabsorbable Zinc-Copper Alloys
}

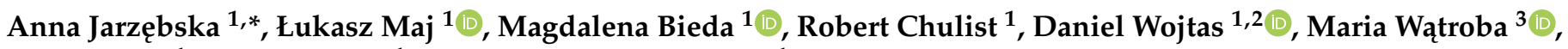 \\ Karol Janus ${ }^{1}$, Lukasz Rogal $^{1}$ and Krzysztof Sztwiertnia ${ }^{1}$ \\ 1 Institute of Metallurgy and Materials Science, Polish Academy of Sciences, 30-059 Krakow, Poland; \\ l.maj@imim.pl (Ł.M.); m.bieda@imim.pl (M.B.); r.chulist@imim.pl (R.C.); Daniel.Wojtas@fis.agh.edu.pl (D.W.); \\ k.janus@imim.pl (K.J.); l.rogal@imim.pl (Ł.R.); k.sztwiertnia@imim.pl (K.S.) \\ 2 Faculty of Physics and Applied Computer Science, AGH University of Science and Technology, \\ 30-059 Krakow, Poland \\ 3 Faculty of Metals Engineering and Industrial Computer Science, AGH University of Science and Technology, \\ 30-059 Krakow, Poland; mwatroba@agh.edu.pl \\ * Correspondence: a.jarzebska@imim.pl
}

check for updates

Citation: Jarzębska, A.; Maj, Ł.; Bieda, M.; Chulist, R.; Wojtas, D.; Wątroba, M.; Janus, K.; Rogal, Ł.; Sztwiertnia, K. Dynamic

Recrystallization and Its Effect on Superior Plasticity of Cold-Rolled Bioabsorbable Zinc-Copper Alloys. Materials 2021, 14, 3483. https:// doi.org/10.3390/ma14133483

Academic Editor: Andrey Belyakov

Received: 21 May 2021

Accepted: 19 June 2021

Published: 23 June 2021

Publisher's Note: MDPI stays neutral with regard to jurisdictional claims in published maps and institutional affiliations.

Copyright: (c) 2021 by the authors. Licensee MDPI, Basel, Switzerland. This article is an open access article distributed under the terms and conditions of the Creative Commons Attribution (CC BY) license (https:// creativecommons.org/licenses/by/ $4.0 /)$.

\begin{abstract}
High plasticity of bioabsorbable stents, either cardiac or ureteral, is of great importance in terms of implants' fabrication and positioning. Zn-Cu constitutes a promising group of materials in terms of feasible deformation since the superplastic effect has been observed in them, yet its origin remains poorly understood. Therefore, it is crucial to inspect the microstructural evolution of processed material to gain an insight into the mechanisms leading to such an extraordinary property. Within the present study, cold-rolled $\mathrm{Zn}-\mathrm{Cu}$ alloys, i.e., $\mathrm{Zn}$ with addition of $1 \mathrm{wt} . \%$ and $5 \mathrm{wt} . \%$ of $\mathrm{Cu}$, have been extensively investigated using scanning electron microscopy as well as transmission electron microscopy, so as to find out the possible explanation of superior plasticity of the $\mathrm{Zn}-\mathrm{Cu}$ alloys. It has been stated that the continuous dynamic recrystallization has a tremendous impact on superior plasticity reported for $\mathrm{Zn}-1 \mathrm{Cu}$ alloy processed by rolling to $90 \%$ of reduction rate. The effect might be supported by static recrystallization, provoking grain growth and thereby yielding non-homogeneous microstructures. Such heterogeneous microstructure enables better formability since it increases the mean free path for dislocation movement.
\end{abstract}

Keywords: bioabsorbable zinc; microstructure; superplasticity; dynamic recrystallization

\section{Introduction}

Zn-based biodegradable alloys have enjoyed a soaring popularity in research over the last couple of years [1,2]. This is mostly because of their compatibility with blood and tissues as well as corrosion rates that could easily go up against those demonstrated by Mg- and Fe-based biodegradable materials [3]. However, in the as-cast state, $\mathrm{Zn}$ and its alloys exhibit abnormally low mechanical properties, and therefore their wide-scale use becomes obstructed. Alloying combined with grain refinement, obtained by e.g., severe plastic deformation (SPD) technologies, has turned into an effective solution eliminating the aforementioned drawbacks [1]. A host of alloying elements, including $\mathrm{Mg}, \mathrm{Ca}, \mathrm{Sr}$, or $\mathrm{Li}$, have been introduced, yielding a wide range of biodegradable metallic materials for medical applications [4]. However, a careful selection of alloying elements is crucial as some of them (e.g., Ag or $\mathrm{Al}$ ) tend to exceptionally strengthen pure $\mathrm{Zn}$, although they may pose a threat to a human body. In fact, Ag might be toxic at high concentrations, while $\mathrm{Al}$ is debated to have a negative impact on the nervous system [5,6]. Therefore, $\mathrm{Cu}$ was proposed as the alloying element.

Copper is an essential microelement of rich history in medical use as a therapeutic or antibacterial agent. It is required for survival and serves as a cofactor for a variety of life-sustaining proteins and metalloenzymes $[7,8]$. It has been reported that various 
Cu-bearing Zn alloys manifest good mechanical properties as well as superplasticity [9-11], a feature of vast importance in terms of implants' fabrication and positioning. Not only bone implants, but also wound closure devices and stents could make use of materials able to harmlessly dissolve in a human body. In fact, biodegradable metals have been mostly proposed as candidates for cardiovascular stents since their usage significantly increases year by year and a long-time service of a stent in clogged artery is not necessary [2]. On the other side, ureteral stents are rarely addressed while researching biodegradable materials [12]. Considering their implantation site, $\mathrm{Zn}$-Cu alloys may be an appropriate choice for the production of ureteral stents due to their antibacterial properties. It is also worth mentioning that in comparison with pure $\mathrm{Zn}, \mathrm{Zn}-\mathrm{Cu}$ alloys are characterized by slightly higher corrosion rates, enabling a material to degrade faster, which is also favorable in terms of ureteral stents [13]. A huge advantage of the $\mathrm{Zn}-\mathrm{Cu}$ system is its high ductility, needed while a stent is inserted into the ureter.

Thus, within the present study, cold-rolled $\mathrm{Zn}$ alloys with the addition of $1 \mathrm{wt} . \%$ and $5 \mathrm{wt} . \% \mathrm{Cu}$ have been studied in detail. Although biodegradable metals are typically investigated with regard to their corrosion and biological behavior [14-17], it is crucial to control the microstructure of a material as it reflects on a host of properties. Moreover, investigation of microstructure evolution during plastic deformation can shed some light on the understanding of deformation mechanisms of the processed materials, yet such an approach has been barely studied in terms of $\mathrm{Zn}-\mathrm{Cu}$ alloys. Therefore, careful microstructure examination of processed $\mathrm{Zn}-\mathrm{Cu}$ alloys was carried out using state-of-the-art techniques such as electron backscatter diffraction (EBSD) and transmission electron microscopy (TEM). Finally, the mechanical properties of the obtained materials were assessed by a set of static tensile tests. The main goal was to reveal the origin of superior plasticity observed in $\mathrm{Cu}$-bearing $\mathrm{Zn}$ alloys, as it has not been completely understood so far.

\section{Materials and Methods}

$\mathrm{Zn}-1 \mathrm{Cu}$ and $\mathrm{Zn}-5 \mathrm{Cu}$ (in wt.\%) alloys, used in the presented experiments, were produced by the gravity casting method. Zinc of $99.99 \mathrm{wt} . \%$ purity and CuZn40 brass were heated up to $650{ }^{\circ} \mathrm{C}$ and melted in a chamotte crucible inside the Nabertherm N20/14 resistance furnace (Lilienthal, Germany) under argon atmosphere. Additionally, the melt was coated with borax in order to avoid oxidation. Next, the $\mathrm{Zn}-1 \mathrm{Cu}$ and $\mathrm{Zn}-5 \mathrm{Cu}$ materials were cast into the steel molds. As a result, cylindrical ingots with a diameter of $40 \mathrm{~mm}$ and a height of $170 \mathrm{~mm}$ were obtained. Subsequently, the ingots were hot-extruded at $280{ }^{\circ} \mathrm{C}$ with the reduction $\mathrm{R}=16$, yielding a rod with a diameter of $10 \mathrm{~mm}$. Finally, the hot-extruded materials were subjected to multi-pass cold-rolling up to $90 \%$ of reduction at room temperature. In order to characterize the microstructural evolution, two additional deformation stages were examined, namely $50 \%$ and $75 \%$ of reduction. The reduction ratio of 3\% for each rolling pass was executed, meaning 10 passes, 15 passes and 18 passes corresponding to the reduction rate of $50 \%, 75 \%$ and $90 \%$, respectively.

The microstructure characterization of the cold-rolled $\mathrm{Zn}-1 \mathrm{Cu}$ and $\mathrm{Zn}-5 \mathrm{Cu}$ alloys was done by means of orientation imaging microscopy (OIM) performed with the help of the EBSD method, using a FEI Quanta 3D 200i FEG-SEM microscope (Eindhoven, The Netherlands) equipped with an EDAX OIM TSL EBSD system ver. 7.0. (Berwyn, IL, USA). The analysis was done on the normal cross-section to the rolling direction (RD). The map of the size of $128 \times 128 \mu \mathrm{m}$ was collected with a step size of $100 \mathrm{~nm}$. Additionally, for samples after the tensile test, data collection was performed on the rolling plane, where the orientation map with the size of $100 \times 100 \mu \mathrm{m}$ and a step size of $60 \mathrm{~nm}$ was gathered. For the sake of better visibility, the presented orientation maps in the results section were cropped to $60 \times 60 \mu \mathrm{m}$; however, all of the acquired data was considered in the calculations (except the points described below). The orientation maps were analyzed using the TSL OIM ver. 7.0 computer software (Berwyn, IL, USA). The grain was defined as a set of at least five measurement points, characterized by the same orientation and separated from a neighboring grain by a high-angle grain boundary with the misorientation an- 
gle exceeding $15^{\circ}$. Additionally, the measurement points with a low confidence index $(\mathrm{CI}<0.1)$ were removed from the calculations. Based on the collected data, grain size, grain boundary character as well as sub-grain characteristic, i.e., grain orientation spread (GOS), were analyzed. The GOS parameter describes the level of local misorientation within a particular grain, indicating distortions in the crystal lattice caused mostly by dislocations e.g., in the form of sub-grains. The higher the value of GOS, the more deformed microstructure has been obtained. On the contrary, a low GOS value represents recrystallized grains. The preparation of the metallographic cross-sections for the SEM/EBSD studies relied on the standard procedure, covering grinding with abrasive papers, ranging from 100 up to 7000 grit, followed by polishing with $1 \mu \mathrm{m}$ and $\frac{1}{4} \mu \mathrm{m}$ diamond suspension. The final step of samples' preparation for SEM/EBSD measurements differed depending on the alloy composition. In the case of $\mathrm{Zn}-1 \mathrm{Cu}$ alloy, electropolishing executed by applying the Struers Lectro-Pol machine (Copenhagen, Denmark) with the C1 Struers electrolyte at $25 \mathrm{~V}$ for $15 \mathrm{~s}$ was performed. For the $\mathrm{Zn}-5 \mathrm{Cu}$ alloy, as the final step, the low-angle $\mathrm{Ar}^{+}$ion polishing for $20 \mathrm{~min}$ and $3.5 \mathrm{kV}$, using a Hitachi IM4000Plus Ion Milling System (Tokyo, Japan), was performed to improve the EBSD pattern quality and remove the deformed layer after mechanical preparation.

Microstructure characterization in the nanoscale was executed with the help of FEI Tecnai G2 SuperTWIN FEG transmission electron microscope (Eindhoven, The Netherlands) operated at $200 \mathrm{kV}$. It is equipped with a SIS MegaView III CCD camera, a Fischione detector and an EDAX energy dispersive X-ray spectrometer (EDS) for the acquisition of microstructure images in the bright field (TEM/BF)/dark field (TEM/DF) modes, together with electron diffraction patterns, STEM/HAADF microphotographs and X-ray spectra for chemical microanalysis. The phase analysis was carried out based on the acquired selected area electron diffraction (SAED) patterns, using CSpot computer software. The samples for TEM inspections were prepared by means of the electropolishing method with the use of a Struers TenuPol-5 machine (Copenhagen, Denmark) with the electrolyte cooled down to $-20{ }^{\circ} \mathrm{C}$ ( $5 \%$ of perchloric acid and $95 \%$ ethanol) operated at $30 \mathrm{~V}$. In addition, a thin lamella was also cut out from the sample after the tensile test with the use of the focused ion beam (FIB) technique, carried out on a ThermoFisher Scios 2 Dual Beam microscope (Eindhoven, The Netherlands), equipped with an EasyLift ${ }^{\mathrm{TM}}$ nanomanipulator.

Mechanical properties were determined by uniaxial static tensile tests. The tests were performed by using an Instron 6025 machine (Norwood, MA, USA) at a room temperature with a constant strain rate of $10^{-3} 1 / \mathrm{s}$. For each cold-rolling parameter, three different samples were cut in the RD as seen in Figure 1.

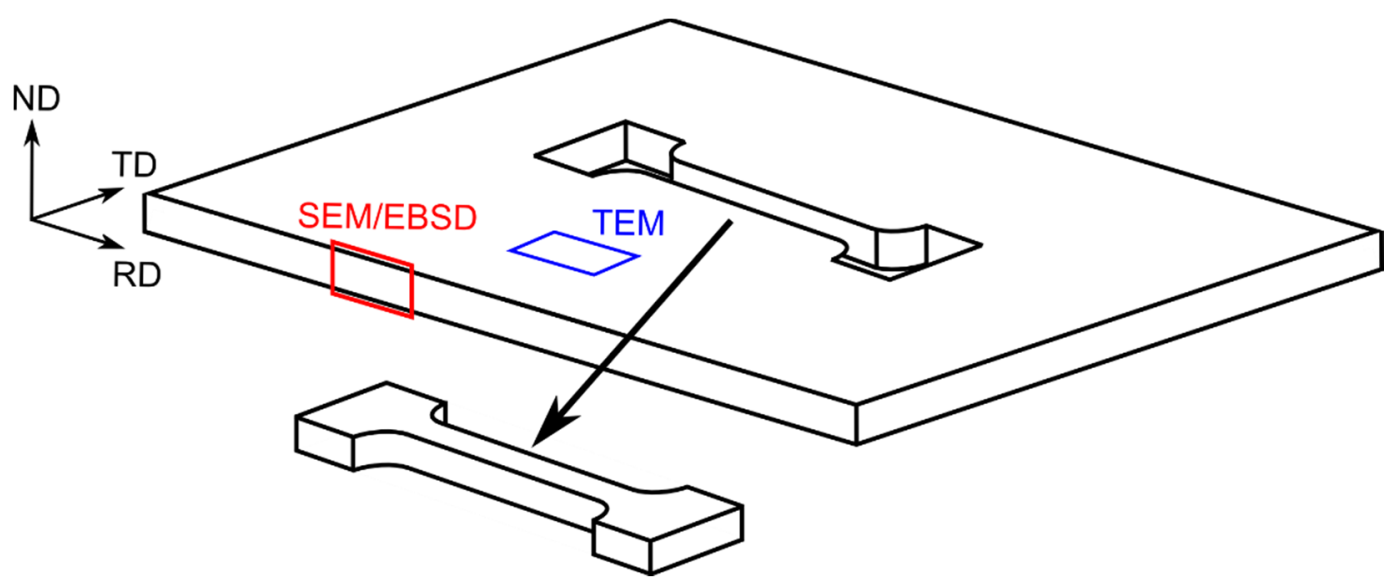

Figure 1. Scheme of cutting samples from $\mathrm{Zn}-\mathrm{Cu}$ sheets for uniaxial tensile test and depicted cross-section of EBSD and TEM investigations. 


\section{Results}

\subsection{SEM/EBSD Characterization of Cold-Rolled Zn-Cu Alloys}

Microstructure of $\mathrm{Zn}-1 \mathrm{Cu}$ alloy deformed by cold-rolling with $90 \%$ of reduction was composed of $\eta-Z n$ grains and small, round-shaped, evenly distributed precipitates rich in $\mathrm{Cu}$. Based on the element distribution map gathered during the EBSD data collection, it was also observed that $\mathrm{Cu}$ was present in the solution as well (Figure 2). An increase in $\mathrm{Cu}$ addition up to $5 \mathrm{wt} . \%$ resulted in a higher volume fraction of the second phase forming almost band-like microstructure elongated in the RD. In $\mathrm{Zn}-5 \mathrm{Cu}$ alloy, except for the larger elongated precipitates, small round ones (as in the $\mathrm{Zn}-1 \mathrm{Cu}$ alloy) were also observed. On the contrary to the $\mathrm{Zn}-1 \mathrm{Cu}$ alloy, depletion of $\mathrm{Cu}$ contained in the solution was noticed.

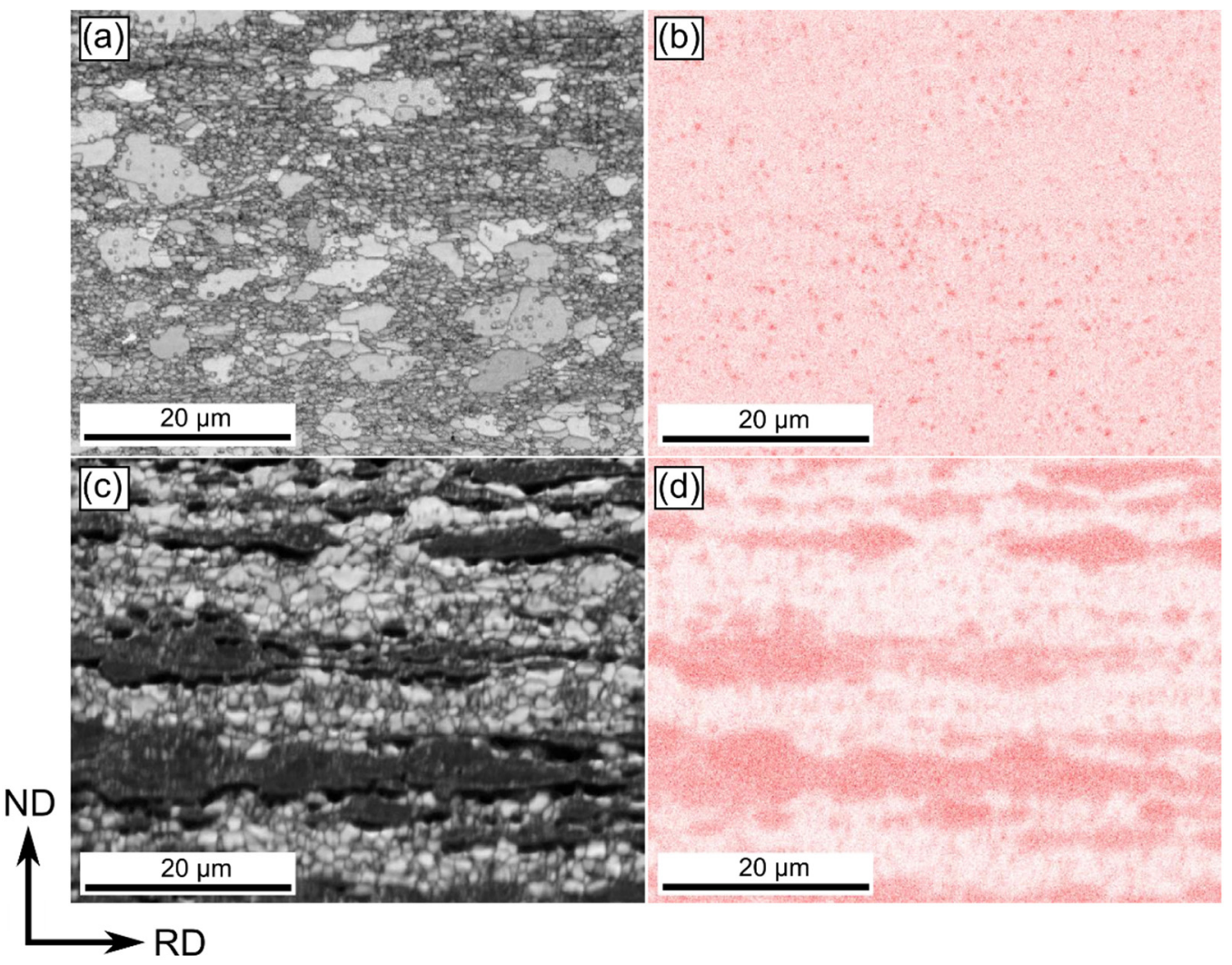

Figure 2. SEM/EBSD image quality map and corresponding $\mathrm{Cu}$ distribution map of samples coldrolled with the reduction rate of $90 \% \mathrm{Zn}-1 \mathrm{Cu}$ alloy $(\mathbf{a}, \mathbf{b})$ and $\mathrm{Zn}-5 \mathrm{Cu}(\mathbf{c}, \mathbf{d})$ alloy.

Systematic analysis by means of orientation mapping during multi-pass cold rolling up to $90 \%$ of reduction performed for both $\mathrm{Zn}-1 \mathrm{Cu}$ and $\mathrm{Zn}-5 \mathrm{Cu}$ alloys on the ND-RD was carried out in the way to allow the microstructural evolution to be monitored. Thus, additional observation on the particular steps of the cold-rolling process, namely with the reduction rates of $50 \%$ and $75 \%$, were chosen. The microstructure of the $\mathrm{Zn}-1 \mathrm{Cu}$ alloy cold-rolled with the reduction rate of $50 \%$ was composed of large, slightly elongated in the $\mathrm{RD}$, and $\eta-Z n$ grains with an average diameter size of $7.7 \pm 6 \mu \mathrm{m}$. In the orientation map presented in Figure 3a, some twins were also distinguished. Moreover, small secondary phases, seen as black areas on the orientation maps (excluded from the calculations due to the low confidence index value), were observed mostly within grains. Cold rolling of the $\mathrm{Zn}-1 \mathrm{Cu}$ alloy with $50 \%$ of the reduction rate caused an accumulation of large number of defects as a higher density of Low Angle Grain Boundaries (LAGBs) compared to High Angle Grain Boundaries (HAGBs) was noticed. An increasing strain provoked a gradual grain refinement as the average values of grain size equaled to $3.6 \pm 3 \mu \mathrm{m}$ and $2.6 \pm 2 \mu \mathrm{m}$ were achieved for $75 \%$ and $90 \%$ of the reduction rate, respectively. Moreover, higher reduction rates caused the formation of heterogeneous microstructures, composed of 
grains elongated in the $\mathrm{RD}$, and coarse and ultra-fine grains. The higher the reduction rate was, the greater the heterogeneity that was obtained. Within the elongated grains, a high density of LAGBs was also observed. In most cases those elongated grains possessed the privileged orientation i.e., the $<0001>$ direction aligned along the RD. A constant increase in HAGB density was observed with the increasing reduction rate. It was also observed that, firstly, a density of LAGBs decreased then increased again for the reduction of $90 \%$, which is depicted in Figure 4.
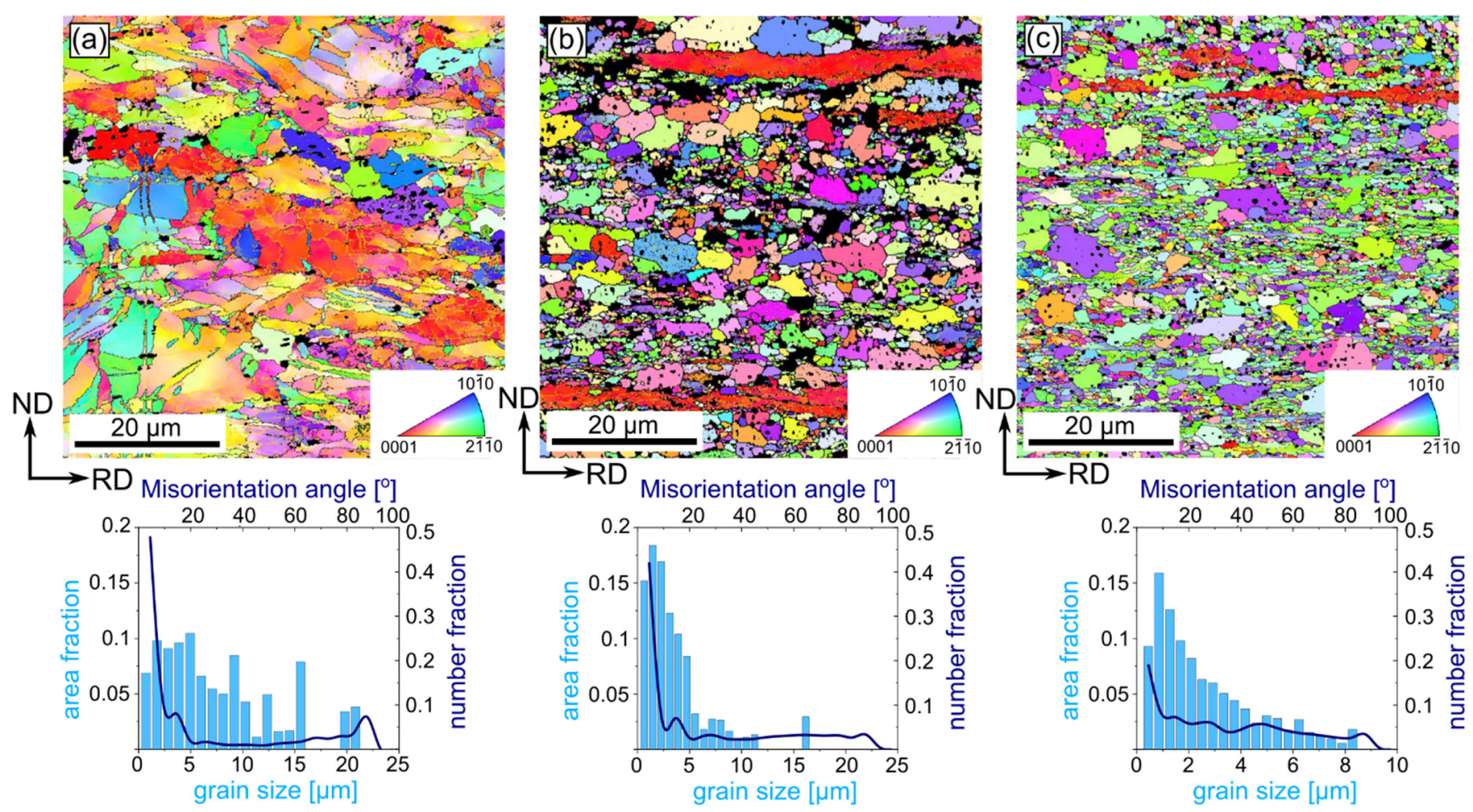

Figure 3. Orientation maps with the corresponding distribution of grain size and misorientation angle of the cold-rolled $\mathrm{Zn}-1 \mathrm{Cu}$ alloy with reduction rate $50 \%$ (a), 75\% (b) and 90\% (c). Dark areas correspond to the second phase and were excluded from the analysis. HAGBs and LAGBs were marked with black and yellow colors, respectively. Orientation maps are color-coded based on the IPF triangle depicted in the right corner with respect to the RD.
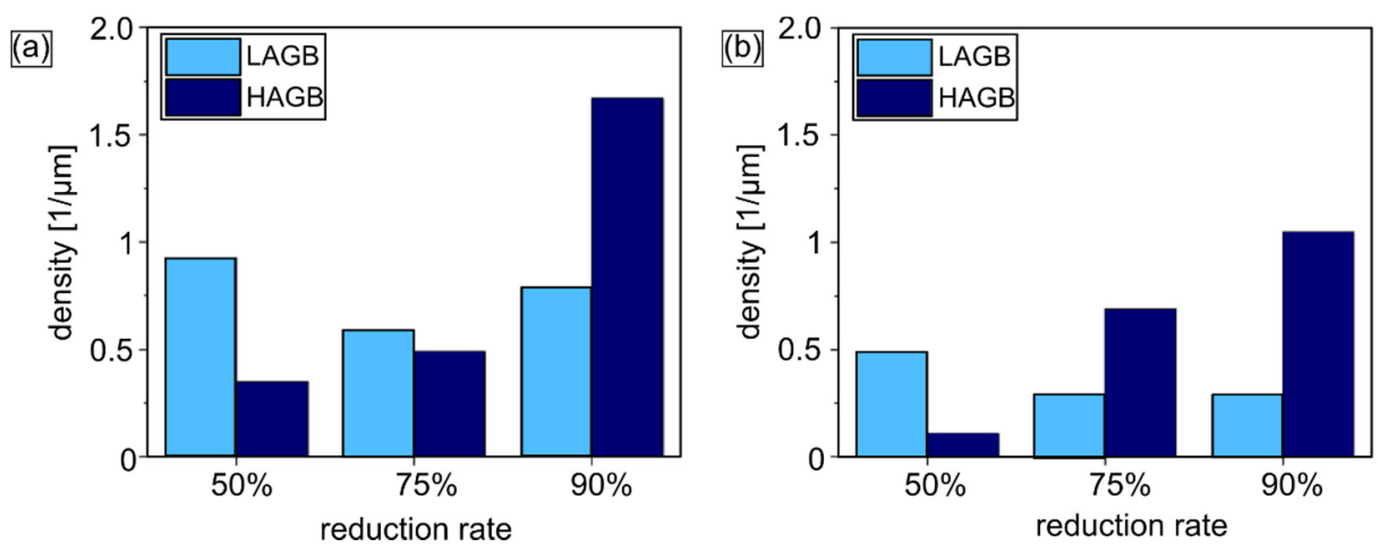

Figure 4. Density of LAGBs and HAGBs obtained for $\mathrm{Zn}-1 \mathrm{Cu}$ (a) and $\mathrm{Zn}-5 \mathrm{Cu}$ (b) alloys cold-rolled with different reduction rates.

An increase of the $\mathrm{Cu}$ addition up to $5 \mathrm{wt} . \%$ provoked the formation of the intermetallic phase, apart from forming small precipitates, transformed into large, elongated in the RD 
band-like structure, covering more than $50 \%$ of the orientation maps area, depicted in Figure 5. The increased fraction of the second phase contributed to smaller average grain size obtained in the $\mathrm{Zn}-5 \mathrm{Cu}$ alloy compared to the $\mathrm{Zn}-1 \mathrm{Cu}$ alloy. Moreover, the $\mathrm{Zn}-5 \mathrm{Cu}$ alloy possessed more homogeneous distribution of grain size and grain shape, indicating that nearly equiaxed grains were observed after different reductions. While investigating the microstructure evolution of the $\mathrm{Zn}-5 \mathrm{Cu}$ alloy, similar conclusions as in the case of the $\mathrm{Zn}-1 \mathrm{Cu}$ alloy can be drawn. An increasing reduction rate caused gradual grain refinement of $\mathrm{Zn}$ alloy with a higher $\mathrm{Cu}$ amount. The average grain size of $3.1 \pm 2 \mu \mathrm{m}, 2.5 \pm 1 \mu \mathrm{m}$ and $1.6 \pm 1 \mu \mathrm{m}$ were achieved for the reduction rates of $50 \%, 75 \%$ and $90 \%$, respectively. However, in the case of the $\mathrm{Zn}-5 \mathrm{Cu}$ alloy those values are smaller than in the $\mathrm{Zn}-1 \mathrm{Cu}$ alloy. Moreover, the higher the reduction rate, the narrower the range of grain size distribution and the higher the fraction of equiaxed grains. Another similarity elicited by cold rolling was that $50 \%$ reduction of the $\mathrm{Zn}-5 \mathrm{Cu}$ alloy resulted in an accumulation of a large density of LAGBs (Figure $4 \mathrm{~b}$ ). An increasing reduction rate decreased the density of LAGBs. Moreover, the number of LAGBs was lower for the $\mathrm{Zn}-5 \mathrm{Cu}$ than for the $\mathrm{Zn}-1 \mathrm{Cu}$. Furthermore, a smaller density of HAGBs was observed for the alloy with higher $\mathrm{Cu}$ addition, what seems unlikely since it is characterized by the smaller grain size. A feasible explanation for this finding can be the fact that the $\mathrm{Zn}-1 \mathrm{Cu}$ alloy wider spread of grain size distribution and numerous elongated, thin grains are observed what increases the overall grain density as compared to the $\mathrm{Zn}-5 \mathrm{Cu}$ alloy. The $\mathrm{Zn}-1 \mathrm{Cu}$ alloy exhibited a high grain boundary density, both LAGB and HAGB, while in the $\mathrm{Zn}-5 \mathrm{Cu}$ alloy, a significant predominance of the HAGB share over LAGB was observed for higher reduction rates (Figure 4).
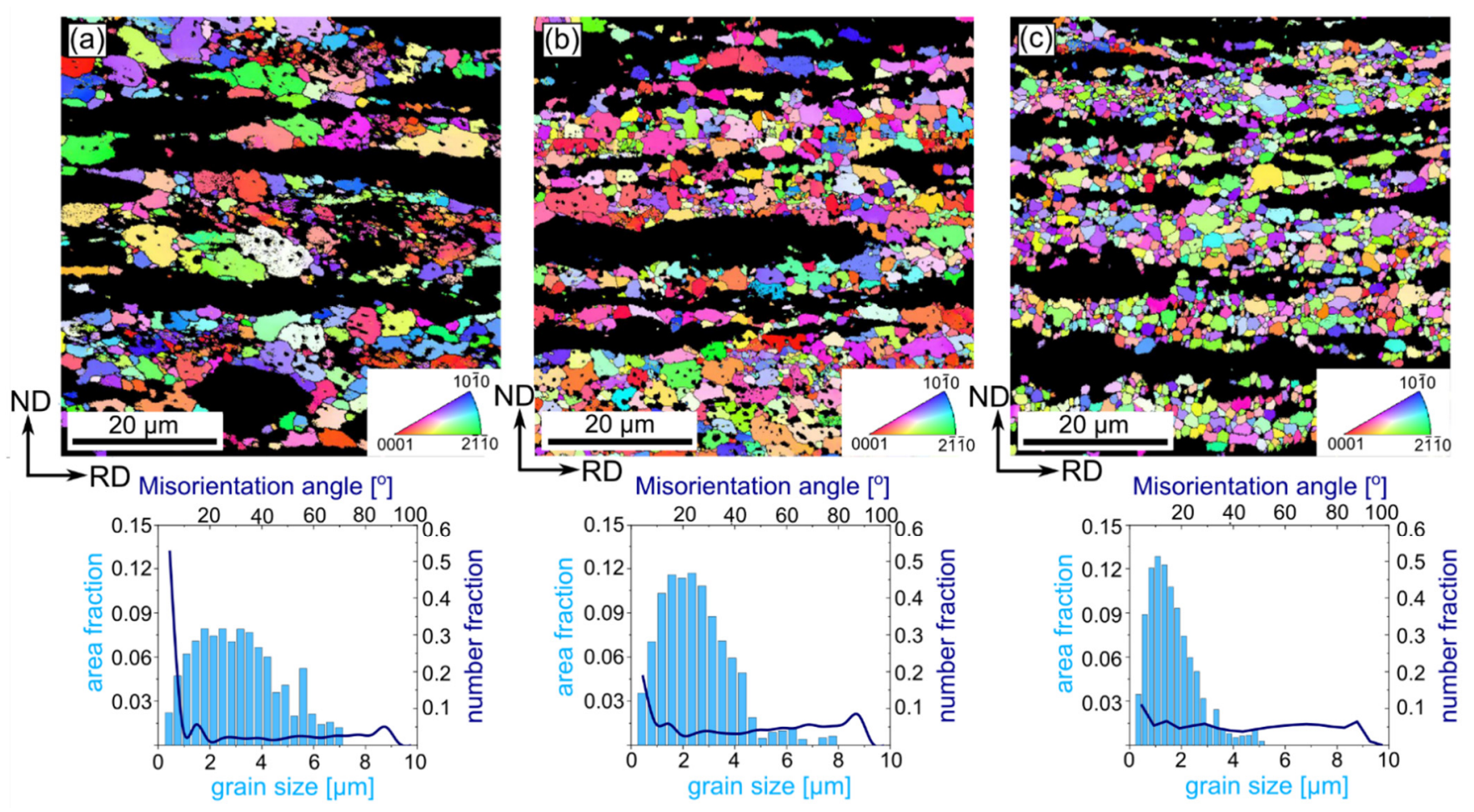

Figure 5. Orientation maps with the corresponding distribution of grain size and misorientation angle of cold-rolled $\mathrm{Zn}-5 \mathrm{Cu}$ alloy with the reduction rate of (a) 50\%, (b) 75\% and (c) 90\%. Dark areas related to the second phase and were excluded form from the analysis. HAGBs and LAGBs were marked with black and yellow colors, respectively. The orientation maps are color-coded based on the IPF triangle depicted in the right corner with the respect to the RD.

Based on the EBSD data, crystallographic texture analysis was also conducted. Figure 6 shows (0002) and (1010) pole figures for all the investigated materials. It can be seen that for both $\mathrm{Zn}-\mathrm{Cu}$ alloys texture gradually evolved with an increasing reduction rate into typical texture observed for cold-rolled hexagonal materials with the $\mathrm{c} / \mathrm{a}$ ratio higher 
than the ideal value of 1.633 [18]. In this case, $<0001>$ direction is tilted away from ND against $\mathrm{RD}$ about $15-20^{\circ}$. Before such texture was achieved, at the beginning of the cold rolling with $50 \%$ of reduction, it was more blurred, but tended to the typical texture for the $\mathrm{Zn}-1 \mathrm{Cu}$ alloy and was more random for $\mathrm{Zn}-5 \mathrm{Cu}$ alloy. The increasing reduction rate to $75 \%$ caused another change in texture formation. In the case of the $\mathrm{Zn}-1 \mathrm{Cu}$ alloy, sharper basal pole tilted toward the $\mathrm{RD}$, as well as the additional components at $90^{\circ}$ in the $\mathrm{RD}$ and the transverse direction (TD), were observed. Similar results were achieved for the $\mathrm{Zn}-5 \mathrm{Cu}$ alloy; however, texture components had lower intensity than for $\mathrm{Zn}-1 \mathrm{Cu}$ alloy. Finally, the typical cold-rolled texture was found for both alloys, except that the $\mathrm{Zn}-1 \mathrm{Cu}$ alloy exhibited higher texture intensity. The received texture implies that plastic deformation of cold rolled $\mathrm{Zn}-\mathrm{Cu}$ alloys resulted from a combination of basal slip and twinning [18].
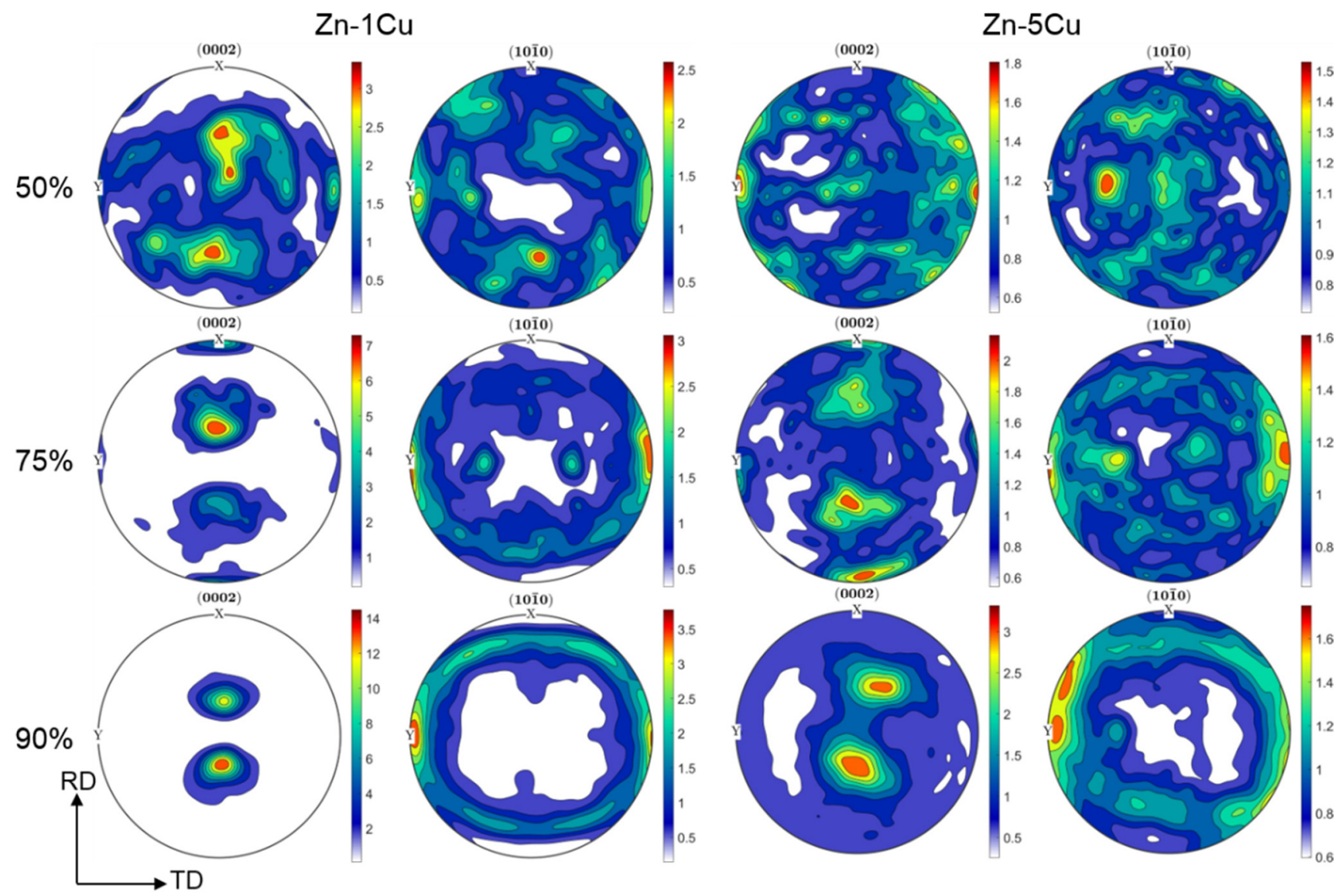

Figure 6. (0002) and (1010) pole figures of the $\mathrm{Zn}-1 \mathrm{Cu}$ (left side) and $\mathrm{Zn}-5 \mathrm{Cu}$ (right side) alloys after cold rolling with reduction rate $50 \%$ (top row), $75 \%$ (middle row) and $90 \%$ (bottom row).

Another microstructural feature that can be calculated based on SEM/EBSD measurements is the GOS parameter. Usually, a value of about $2^{\circ}$ is considered to be specific for recrystallized grains [19]. Recently, Hadadzadeh et al. proposed a new GOS approach to analyze the Dynamic Recrystallization (DRX) and set $5^{\circ}$ as a limit value to separate deformed grains from recrystallized ones [19]. Such an approach worked well in our studies and, thus, $5^{\circ}$ was used to distinguish DRXed from deformed grains in the cold-rolled $\mathrm{Zn}-\mathrm{Cu}$ alloys. Moreover, for all materials the same scale was fixed with maximum value of 25 marked with red color indicating the highest heterogeneity within the particular grain. 
GOS maps, depicted in Figures 7 and 8, indicate that the $\mathrm{Zn}-\mathrm{Cu}$ alloys cold-rolled with the reduction of $50 \%$ exhibited the highest GOS parameter. The increasing reduction rate caused that the number of recrystallized grains increased. A higher GOS parameter was observed for the $\mathrm{Zn}-1 \mathrm{Cu}$ alloy as compared to the $\mathrm{Zn}-5 \mathrm{Cu}$ alloy, regardless of the reduction rate. Moreover, the GOS maps indicated that larger distortion was present within elongated grains, but they are not the only exception. Some parts of coarse grains also exhibited local misorientation. This may also be seen on the GOS charts, indicating that with the increasing reduction rate, the area fraction of grains with the GOS value $2-5^{\circ}$ increased, which also corresponds to the DRXed deformed grains [19].

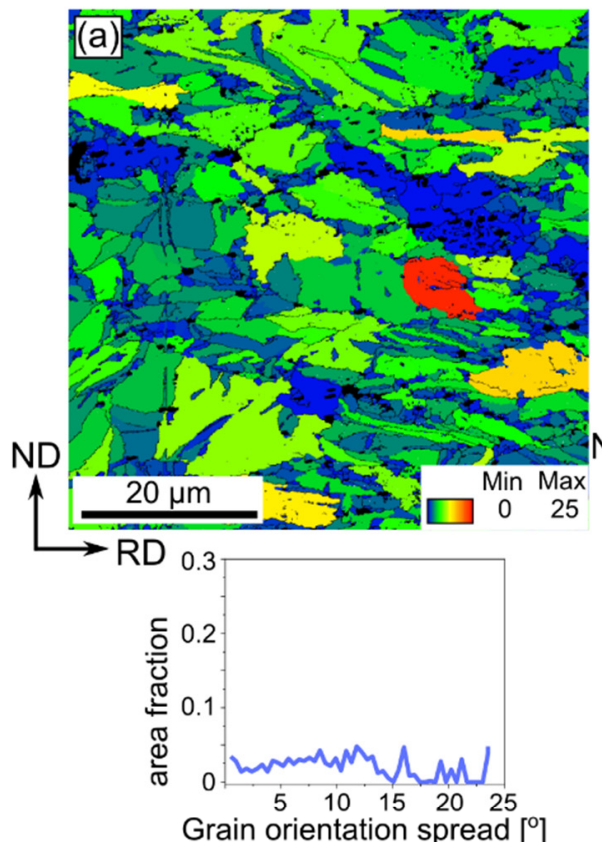

DRXed grains: deformed grains:

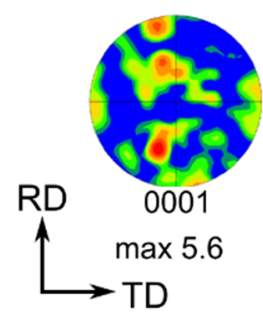

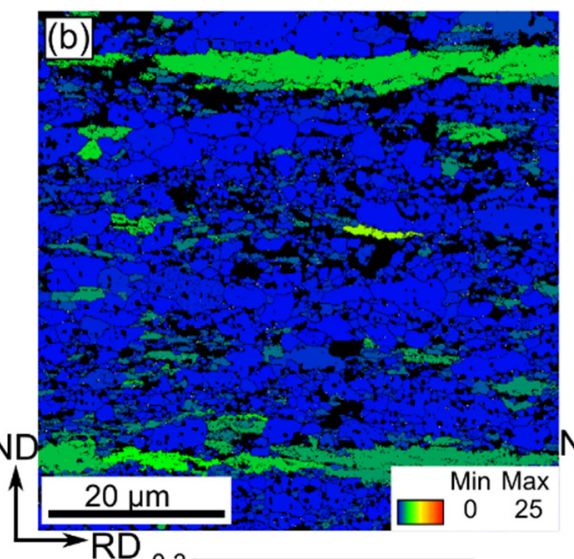

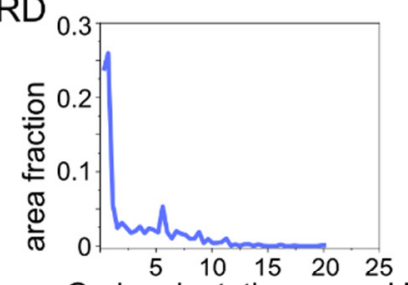
Grain orientation spread $\left[^{\circ}\right]$

DRXed grains: deformed grains:

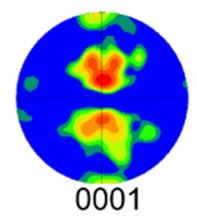

$\max 6.4$

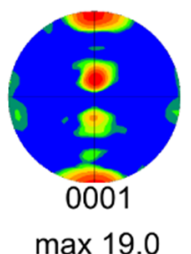

$\max 19.0$

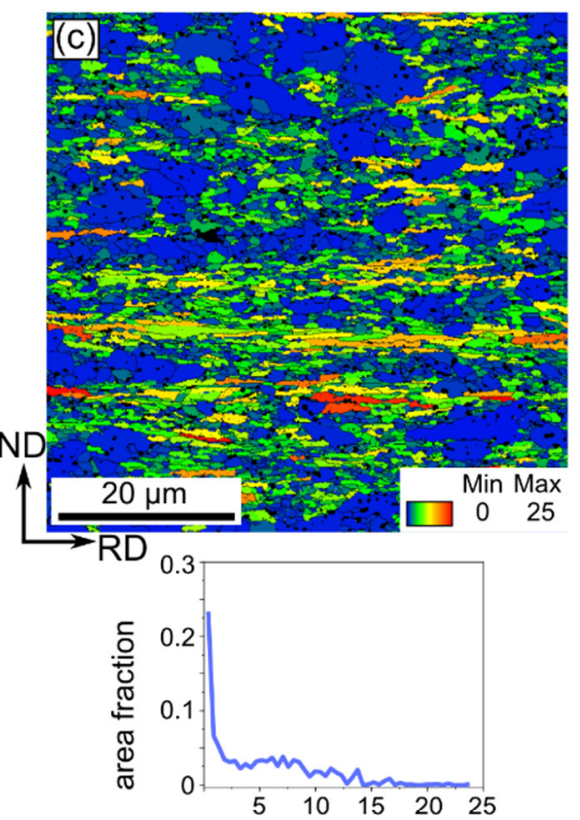

Grain orientation spread [ $\left.{ }^{\circ}\right]$

DRXed grains:

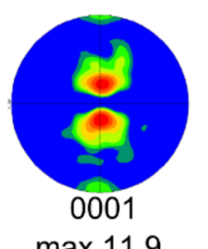

deformed grains:

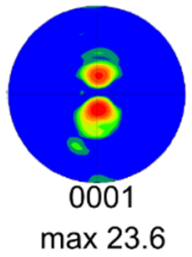

Figure 7. GOS maps with the parameter distribution and below (0001) pole figures of separate based on GOS parameter fraction of DRXed grains (GOS $\leq 5^{\circ}$ ) and deformed grains (GOS $>5^{\circ}$ ) of the cold-rolled $\mathrm{Zn}-1 \mathrm{Cu}$ alloy with the reduction rates of $50 \%(\mathbf{a}), 75 \%(\mathbf{b})$ and $90 \%(\mathbf{c})$.

After dividing grains into two groups, the crystallographic microtexture was determined. The results revealed that DRXed grains followed the texture of deformed grains, even though the texture was more blurred and of lower intensity.

Table 1 summarizes the microstructural characteristics of cold-rolled $\mathrm{Zn}-\mathrm{Cu}$ alloys obtained based on EBSD measurements. 


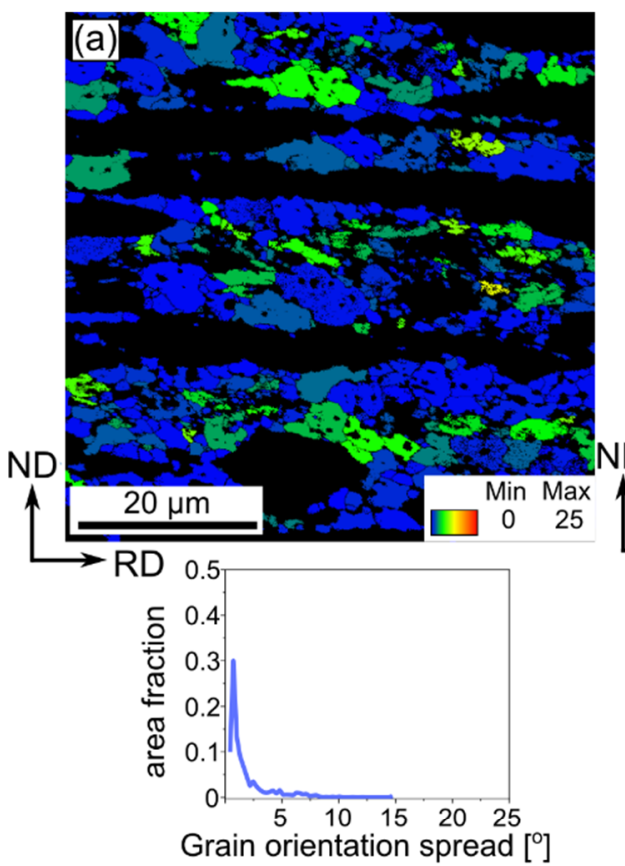

DRXed grains: deformed grains:

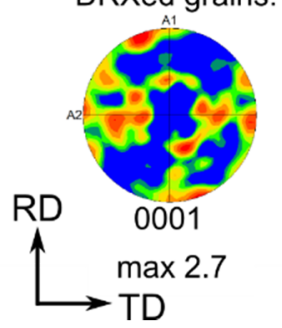

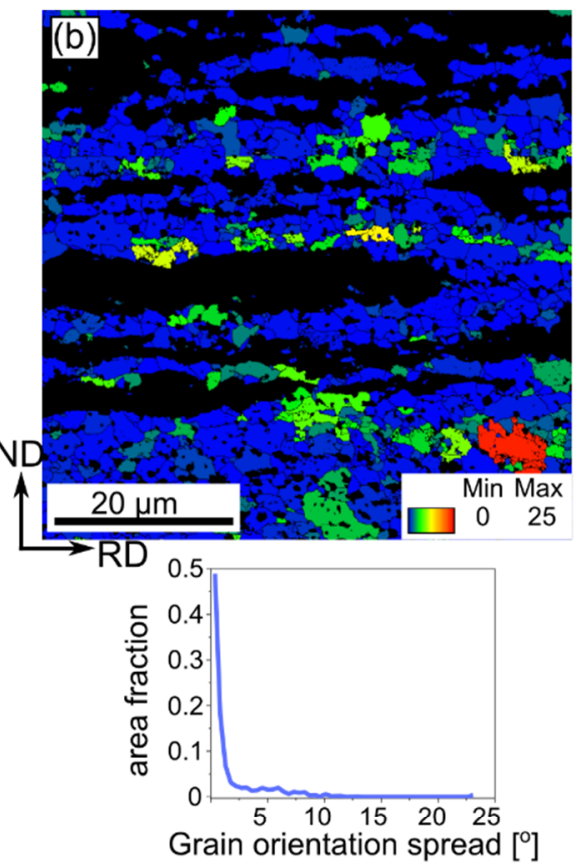

DRXed grains:

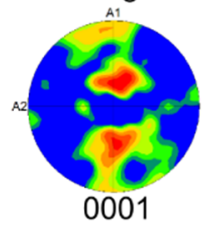

$\max 3.3$ deformed grains:

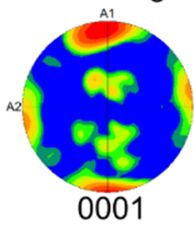

$\max 12.7$

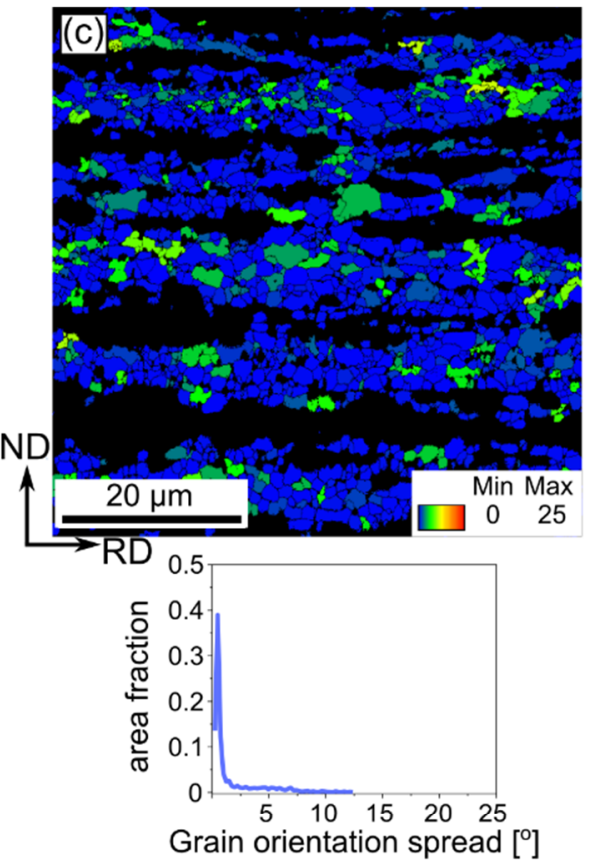

DRXed grains:

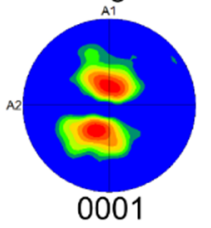

$\max 5.5$

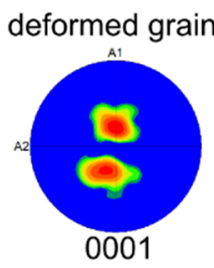

$\max 14.3$

Figure 8. GOS maps with the parameter distribution and below (0001) pole figures of separate based on GOS parameter fraction of DRXed grains (GOS $\leq 5^{\circ}$ ) and deformed grains $\left(\mathrm{GOS}>5^{\circ}\right.$ ) of the cold-rolled $\mathrm{Zn}-5 \mathrm{Cu}$ alloy with the reduction rates of $50 \%($ a), $75 \%($ b) and $90 \%$ (c).

Table 1. List of microstructural characteristics of cold-rolled $\mathrm{Zn}-1 \mathrm{Cu}$ and $\mathrm{Zn}-5 \mathrm{Cu}$ alloys.

\begin{tabular}{|c|c|c|c|c|c|c|}
\hline \multirow[b]{2}{*}{ Reduction rate } & \multicolumn{3}{|c|}{ Zn-1Cu Alloy } & \multicolumn{3}{|c|}{ Zn-5Cu Alloy } \\
\hline & $50 \%$ & $75 \%$ & $90 \%$ & $50 \%$ & $75 \%$ & $90 \%$ \\
\hline Average grain size $[\mu \mathrm{m}]$ & $7.7 \pm 6$ & $3.6 \pm 3$ & $2.6 \pm 2$ & $3.1 \pm 2$ & $2.5 \pm 1$ & $1.6 \pm 1$ \\
\hline $\begin{array}{c}\text { Average misorientation } \\
\text { angle }\left[{ }^{\circ}\right]\end{array}$ & 25 & 27 & 34 & 25 & 43 & 44 \\
\hline Average GOS $\left[{ }^{\circ}\right]$ & $9.9 \pm 6$ & $2.8 \pm 3$ & $4.8 \pm 5$ & $1.9 \pm 2$ & $1.8 \pm 3$ & $1.7 \pm 2$ \\
\hline HAGB density $[1 / \mu \mathrm{m}]$ & 0.35 & 0.49 & 1.67 & 0.11 & 0.69 & 1.05 \\
\hline LAGB density $[1 / \mu \mathrm{m}]$ & 0.93 & 0.59 & 0.79 & 0.49 & 0.29 & 0.29 \\
\hline Fraction of $\mathrm{CuZn} \mathrm{n}_{4}[\%]$ & 6.1 & 26.6 & 10.5 & 60.5 & 50.7 & 56.1 \\
\hline
\end{tabular}

\subsection{TEM Nanoscale Characterization of Cold-Rolled Zn-Cu Alloys}

TEM investigations were performed in order to provide complementary information to the data obtained during SEM/EBSD experiments. Simultaneously, they were focused on the nanoscale characterization of the areas excluded from the orientation maps. The observations executed in the bright-field mode indicated that the microstructure of both the $\mathrm{Zn}-1 \mathrm{Cu}$ and $\mathrm{Zn}-5 \mathrm{Cu}$ alloys cold-rolled with the reduction rate of $50 \%$ is composed of large $\eta-Z n$ grains with uniformly distributed crystal defects of high density (Figure 9a,d). With the increase in the deformation rate, the microstructure remodeling may be noticed as the defects tended to rearrange and group into the low angle grain boundaries (Figure 9b,e). 
Cold rolling with the reduction rate of $90 \%$ resulted in the formation of the microstructure with greater number of defect-free crystallites as compared to lower reduction rates (Figure $9 \mathrm{c}, \mathrm{f}$ ). For the reduction rates of $90 \%$ and $75 \%$ for the $\mathrm{Zn}-1 \mathrm{Cu}$ and $\mathrm{Zn}-5 \mathrm{Cu}$ alloys, respectively, one may also observe the formation of the small precipitates, of equiaxed or lenticular shape, with a size approaching $1 \mu \mathrm{m}$. Simultaneously, the number of these precipitates increased with an increase in the cold-rolling reduction rate. The STEM/HAADF imaging revealed that their formation occurred not only at grain boundaries and triple points, but also within the $\eta-Z n$ crystallites, thanks to the contrast, originating from different atomic numbers of $\eta-Z n$ and the precipitates (Figure 9a). The phase analysis of small precipitates was done through the indexing of the spots presented in the SAED pattern, recorded from one of those crystallites, and allowed to identify them as the $\varepsilon-\mathrm{CuZn}_{4}$ phase (Figure 10b) [20]. In addition, the EDS characterization aimed at determining the chemical elements distribution and the quantitative analysis of precipitates was also carried out by acquiring the spectra from different measurement points (Figure 10). The EDS mapping confirmed the maxima of $\mathrm{Cu}$ concentration within the $\mathrm{CuZn}_{4}$ precipitates pinpointed by the SAED phase analysis. The quantitative chemical analysis enabled for a determination of their chemical composition as $12.3 \pm 1.3 \%$ and $87.7 \pm 1.3 \%$ (in at. \%) for $\mathrm{Cu}$ and $\mathrm{Zn}$, respectively. Moreover, a small amount of $\mathrm{Cu}$ was also dissolved in the $\eta$-Zn grains, forming a solid solution.
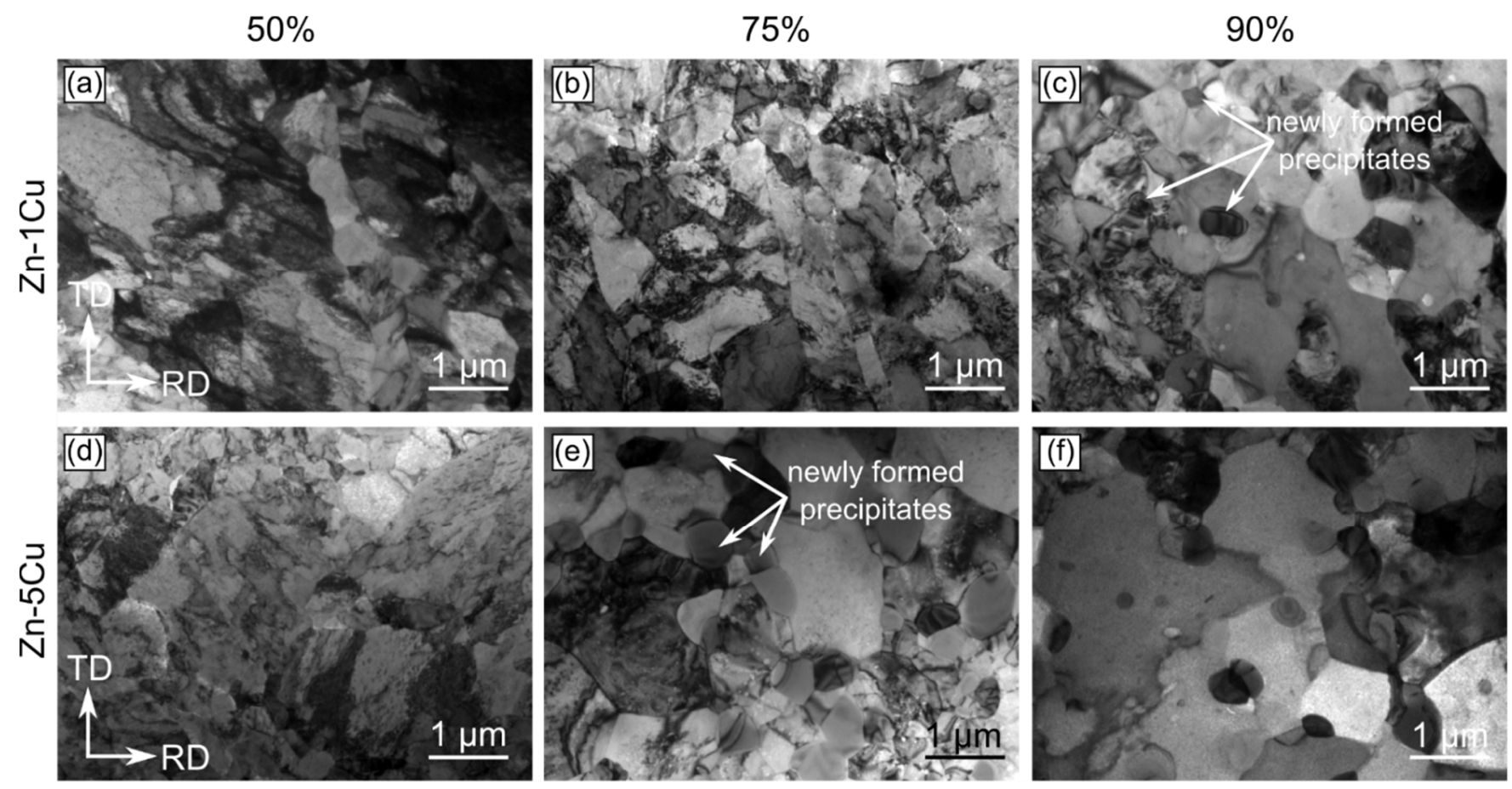

Figure 9. TEM/BF microstructure images of $\mathrm{Zn}-1 \mathrm{Cu}$ and $\mathrm{Zn}-5 \mathrm{Cu}$ alloys subjected to cold-rolling with reduction rate of $50 \%$ $(\mathbf{a}, \mathbf{d}), 75 \%(\mathbf{b}, \mathbf{e})$ and $90 \%(\mathbf{c}, \mathbf{f})$.

\subsection{Mechanical Properties of Cold-Rolled Zn-Cu Alloys}

Mechanical tests revealed that the highest strength was observed for the $\mathrm{Zn}-5 \mathrm{Cu}$ alloy cold-rolled with $50 \%$ of reduction i.e., YS $=156 \mathrm{MPa}$ and UTS $=240 \mathrm{MPa}$. In the Zn-1Cu alloy, the highest YS =142 MPa and UTS = $203 \mathrm{MPa}$ were also achieved after cold-rolling with the reduction rate of $50 \%$. Further increase in the reduction rate caused a decrease in mechanical strength for both materials, yielding UTS = $143 \mathrm{MPa}$ and $116 \mathrm{MPa}$ for the $\mathrm{Zn}-1 \mathrm{Cu}$ alloy after cold rolling with the reduction of $75 \%$ and $90 \%$, respectively, and for the $\mathrm{Zn}-5 \mathrm{Cu}$ alloy: UTS $=182 \mathrm{MPa}$ (reduction rate $75 \%$ ) and UTS $=144 \mathrm{MPa}$ (reduction rate $90 \%$ ). A higher strength obtained for the $\mathrm{Zn}-5 \mathrm{Cu}$ alloy can be substantiated by the higher amount of $\mathrm{Cu}$ addition, which contributed to the formation of numerous second phases, 
strengthening the material. On the contrary, the increasing reduction rate resulted in a substantial increase in elongation of the $\mathrm{Zn}-\mathrm{Cu}$ alloys and in the case of $\mathrm{Zn}-1 \mathrm{Cu}$ cold-rolled with $90 \%$ of reduction, the superplastic effect was observed $(E=272 \%)$.
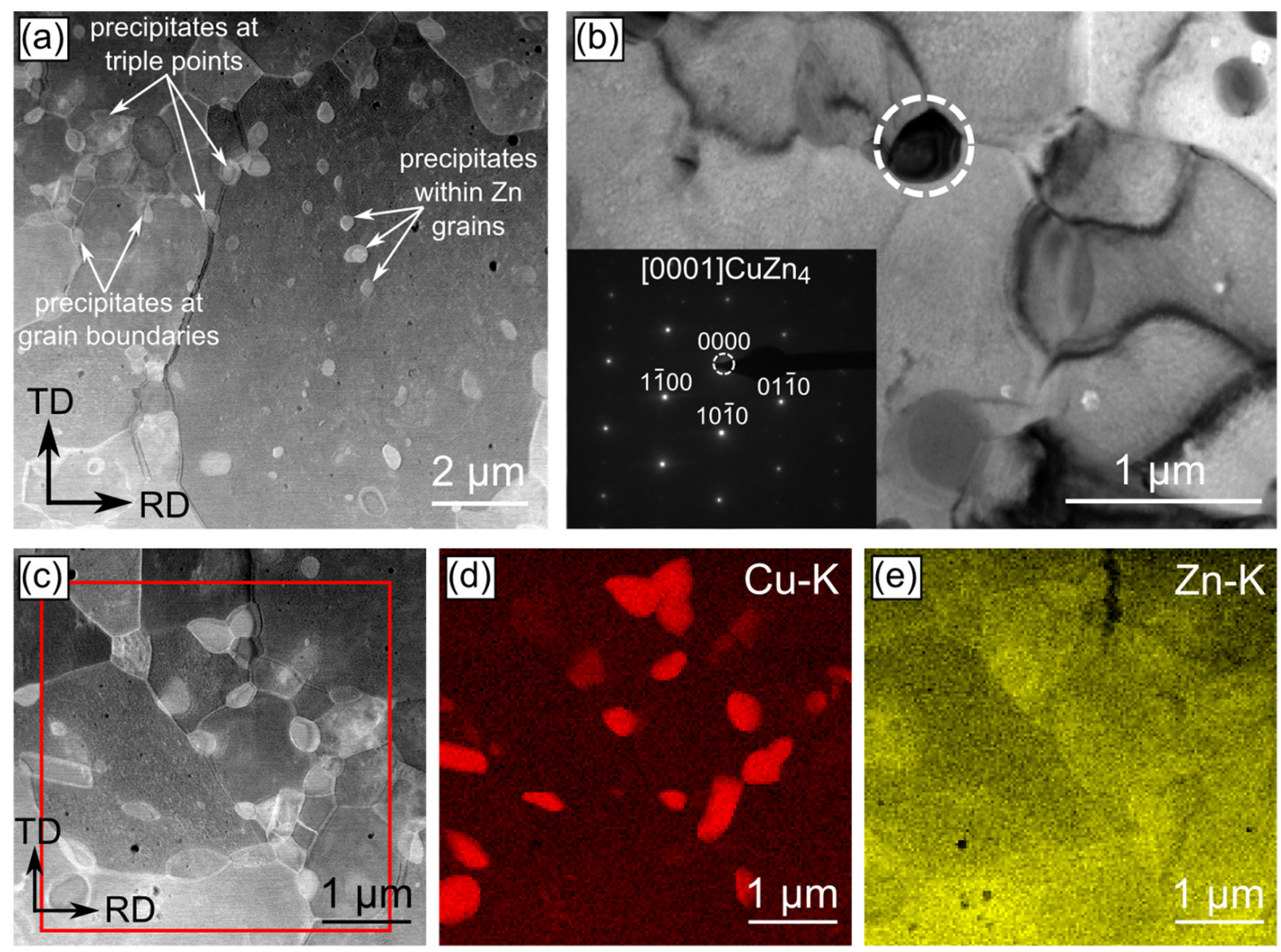

Figure 10. STEM/HAADF (a,c) and TEM/BF (b) microstructure images presenting the $\mathrm{CuZn}_{4}$ precipitates within the $\mathrm{Zn}-1 \mathrm{Cu}$ alloy subjected to cold-rolling with reduction rate of $90 \%$ as well as the EDS maps showing distribution of $\mathrm{Cu}(\mathbf{d})$ and $\mathrm{Zn}(\mathbf{e})$.

Stress-strain curves showed that the $\mathrm{Zn}-5 \mathrm{Cu}$ alloy exhibited a wide range of strainhardening to about $15 \%$, which was higher than for the $\mathrm{Zn}-1 \mathrm{Cu}$ alloy of at least $5 \%$ (Figure 11). After reaching a critical value, the strain-softening effect was observed for all of the investigated materials. Moreover, single or multiple serrations were observed on strain-stress curves for the reduction rates of $50 \%$ and $90 \%$, which are assumed to be related to twinning. 

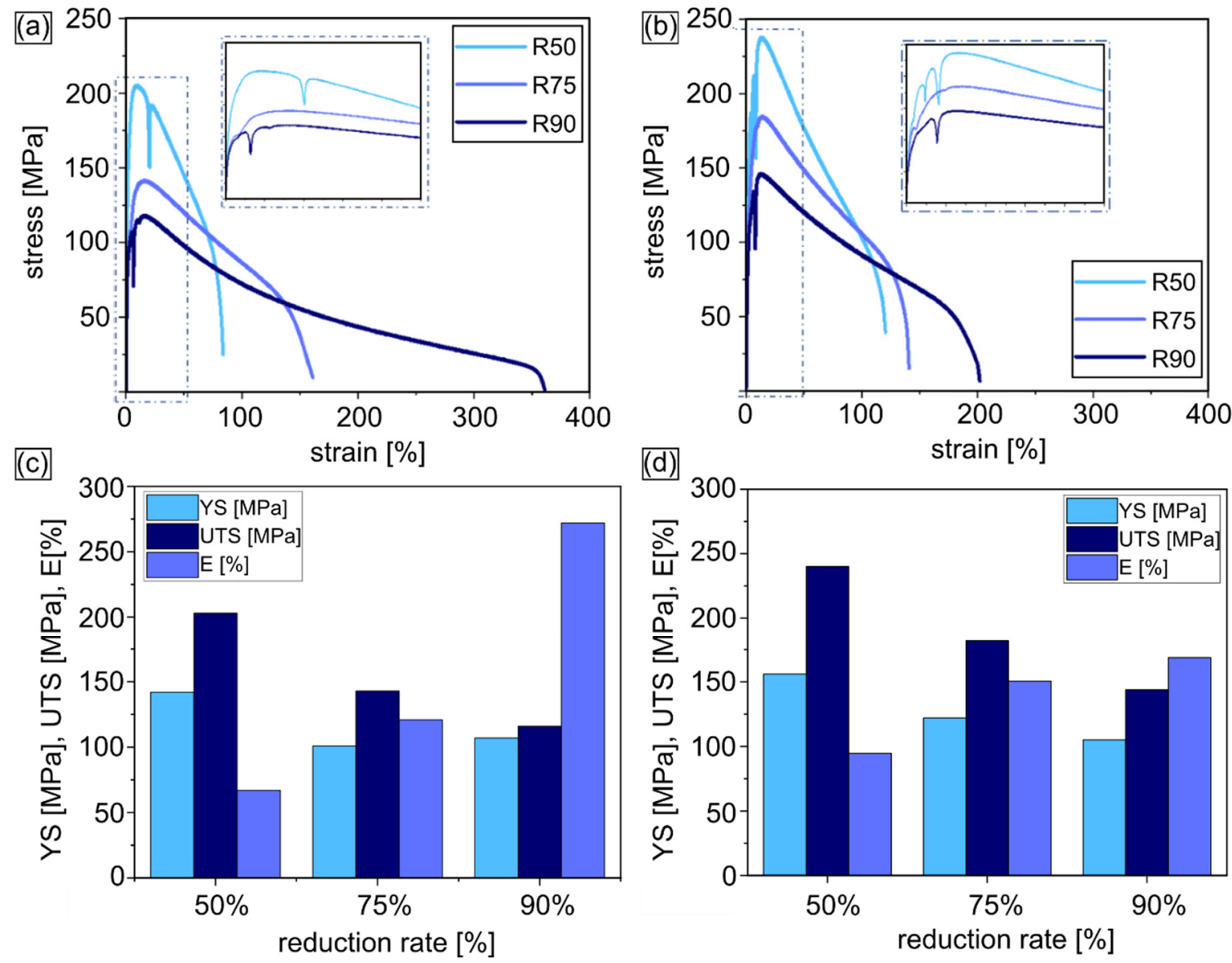

Figure 11. Strain-stress curves (for better visibility dashed line area was magnified and showed above original curves) of coldrolled with different reduction rate $\mathrm{Zn}-1 \mathrm{Cu}$ alloy (a) and $\mathrm{Zn}-5 \mathrm{Cu}$ alloy (b) and corresponding mechanical properties (c,d).

\section{Discussion}

\subsection{Continuous Dynamic Recrystallization in Cold-Rolled Zn-Cu Alloys}

Investigations of microstructure evolution of the $\mathrm{Zn}$-Cu alloys during cold rolling up to $90 \%$ of reduction rate were performed in the present work. Plastic deformation contributed to the significant accumulation of structural defects, especially at the very beginning. It has been proved by the high values of the GOS parameter as well as the high density of LAGBs for the $\mathrm{Zn}-\mathrm{Cu}$ alloys with a reduction of $50 \%$. With the increasing reduction rate, gradual transformation of LAGBs into HAGBs was observed, as revealed by the EBSD and TEM studies, manifesting the occurrence of continuous dynamic recrystallization process (CDRX) [21]. Such mechanism allowed for grain refinement of the $\mathrm{Zn}-\mathrm{Cu}$ alloys, where small equiaxed and defect-free grains were seen in both the orientation maps and TEM microstructure images. Similar microstructural evolution, including the reduction of the LAGBs density in favor of a higher amount of small dynamically recrystallized (DRXed) grains and higher HAGBs density, was shown for the cold-rolled Zn-Ag-Mg alloy for progressively increased cold rolling reduction rates resulting ultimately in superior plasticity after the reduction rate of $90 \%$ [22]. Additionally, due to the investigation of the GOS parameter and separation of a fraction of DRXed grains from deformed ones, it was also possible to support the evidence of CDRX, since the obtained texture of the DRXed grains followed the texture of deformed grains. A more pronounced effect of CDRX was observed for the $\mathrm{Zn}-5 \mathrm{Cu}$ alloy, where systematic drop in LAGBs density in addition to the decrease of the grain size with increasing reduction rate was reported. In the case of $\mathrm{Zn}-1 \mathrm{Cu}$, the effect of CDRX in forming refined, equiaxed micro-structure was limited due to the static recrystallization process, which caused grain growth and heterogeneous 
microstructure. The contribution of CDRX to grain refinement of Zn-based materials was also observed for other methods of plastic deformation such as Equal Channel Angular Pressing (ECAP) or hydrostatic extrusion [9,23-27].

\subsection{Superior Plasticity of Cold-Rolled $\mathrm{Zn}$-Cu Alloys}

It is suggested that DRX not only determined the microstructural changes but also affected mechanical properties. The observed decrease in strength of $\mathrm{Zn}-\mathrm{Cu}$ alloys with the increasing reduction rate was caused by DRX, which is known to play a crucial role in softening during deformation $[21,28]$. Simultaneously, DRX largely contributes to better formability of a material [29]. The results revealed that with the increasing reduction rate, a remarkable increase in elongation of the $\mathrm{Zn}-\mathrm{Cu}$ alloys was achieved. Similar observations were reported by Liu et al. while subjecting pure $\mathrm{Zn}$ to compression at ambient temperature $[29,30]$. They compressed as-cast pure $\mathrm{Zn}$ to the true strain of $161 \%$ and investigated microstructure on different stages of deformation. Their observation revealed that such outstanding plasticity originated from the abundant operation of CDRX supported by twinning-induced dynamic recrystallization (TDRX), which leads to the relaxation of local stresses [29]. In our work, the predominant effect of CDRX was reported, however TDRX seems to be active as well, since on the stress-strain curves the indication of twins was observed.

Thus, it is evident that the occurrence of CDRX plays a significant role in materials formability. However, the results indicate that the effect of DRX on superior plasticity can be intensified by the static recrystallization process. Increasing strain rate caused generation of heat, which for $\mathrm{Zn}$ - a material with recrystallization temperature close to room temperature-was high enough to start the recrystallization process of some grains after a single pass of cold-rolling. Thus, this is the reason for obtaining the heterogeneous microstructure of the $\mathrm{Zn}-1 \mathrm{Cu}$ alloy deformed with the reduction rate of $75 \%$ and $90 \%$. Increasing amount of $\mathrm{Cu}$ addition up to $5 \mathrm{wt}$.\% suppressed the described effect, due to the presence of $\mathrm{CuZn}_{4}$ phases, forming the band-like structures, which were a barrier for dislocation movement and prevented grain growth. It was found that $\mathrm{CuZn}_{4}$ phase can serve as a Particle Stimulated Nucleation place and, therefore, promotes the recrystallization process [15]. However, our results indicate that the bands of the $\mathrm{CuZn}_{4}$ phase also act as obstacles for grain boundary movement and inhibit grain growth.

Due to the increased number of $\varepsilon$-phase precipitates forming a band-like microstructure, the $\mathrm{Zn}-5 \mathrm{Cu}$ alloy exhibited a more homogeneous distribution of grain size and grain shape than the $\mathrm{Zn}-1 \mathrm{Cu}$ alloy. The second phase contributed to the higher strength of the $\mathrm{Zn}-5 \mathrm{Cu}$ alloy and greater strain-hardening. Despite strengthening by second phases the DRX occurred, leading to stress relaxation and provoked materials softening. The lower value of elongation in the $\mathrm{Zn}-5 \mathrm{Cu}$ alloy, beside hindering dislocation motion due to the $\varepsilon$-phase, can be explained by smaller grain size and, as a consequence, the increased fraction of HAGB, another obstacle for dislocation movement.

As a matter of fact, the coarse grains present in the $\mathrm{Zn}-1 \mathrm{Cu}$ alloy seem to be beneficial for plasticity improvement. The coarse-grain twinning is more likely to occur, which subsequently can enhance the effect of DRX, resulting ultimately in a higher elongation. Additionally, larger grain size increases a mean free path for dislocation movement so the dislocation can form sub-grains divided by LAGBs and gradually transform these LAGBs into HAGBs. Thus, it is possible for large grains to get refined through CDRX and some newly DRXed grains can grow in size and subsequently undergo deformation once more and eventually recrystallize statically. Therefore, this process can be repeated and leads to an improvement in the $\mathrm{Zn}$-Cu formability. This hypothesis can be supported by comparing microstructure of the $\mathrm{Zn}-1 \mathrm{Cu}$ alloy cold rolled with a reduction rate of $75 \%$ and that of $90 \%$. In both cases the heterogeneous microstructure was observed and for the reduction of $90 \%$, the number of LAGBs increased as well as the number of refined grains, as compared to the reduction of $75 \%$. In order to find a possible explanation for what may have stopped this process, the additional observation of the $\mathrm{Zn}-1 \mathrm{Cu}$ alloy with $90 \%$ of reduction after the 
uniaxial tensile test was performed. The orientation map presented in Figure 12 showed the microstructure with even more refined grains than in the sample before mechanical testing as the average grain size $2 \pm 1 \mu \mathrm{m}$, was achieved. Moreover, the obtained grains possessed a strong basal texture, in which the basal planes are parallel to the rolling plane. It was reported by Liu et al. that such texture is a "hard-orientation" and thus enables basal slip and twinning to operate [29]. Furthermore, it was shown that the basal texture retards DRX. Our investigation can support such an observation, since, on the orientation maps obtained for the $\mathrm{Zn}-1 \mathrm{Cu}$ alloy cold-rolled with the $75 \%$ of reduction rate, elongated grains also possessed hard orientation and were still present on the orientation maps with the reduction of $90 \%$, but were finer. Thus, during tensile tests, due to initial, typical cold rolling texture, the dislocation slip operated in the basal system, leading eventually to the sharp basal texture. At the beginning, the dislocations movement provoked hardening and subsequently, due to the recovery process, caused their annihilation and formation of subgrains. Under the strain, sub-grains can rotate into HAGBs and CDRX operates, which can explain the observed grain refinement after tensile testing. When finally hard orientation is achieved, there is no possible stress relaxation by DRX and, thus, necking appears and the sample fractures. This texture rotation can be supported by mechanical twinning as its presence was confirmed on the stress-strain curves, which could also facilitate DRX [29,30]. In general, it is believed that the observed superior plasticity in the $\mathrm{Zn}-1 \mathrm{Cu}$ alloy coldrolled with the reduction of $90 \%$ was provoked by dynamic recovery and recrystallization processes, which eliminates the effects of hardening elicited by deformation. The effects of hardening and softening compete with each other until the hard orientation occurs and hinders both of the effects.
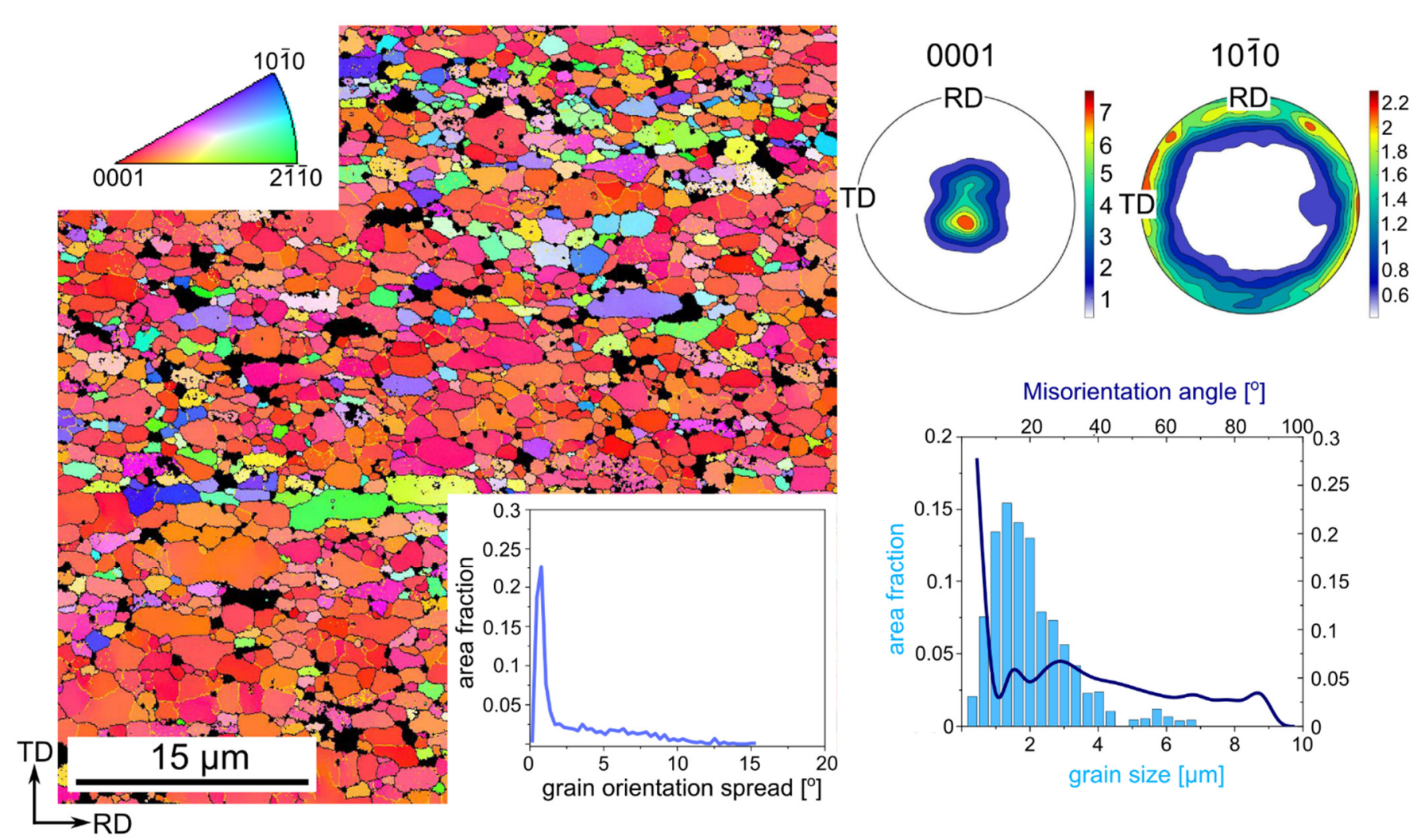

Figure 12. Orientation map with the GOS chart, (0001) and (1010) pole figures and distribution of grain size and misorientation angle of the cold-rolled $\mathrm{Zn}-1 \mathrm{Cu}$ alloy with the reduction rate of $90 \%$ acquired from the necking of the sample after tensile test. Dark areas related to the $\mathrm{CuZn}_{4}$ phase were excluded from the analysis. HAGBs and LAGBs were marked with black and yellow colors, respectively. The orientation map is color-coded based on the IPF triangle depicted in the right upper corner with respect to the ND. 
The room-temperature superplastic effect in $\mathrm{Zn}-\mathrm{Cu}$ alloys was already proven while performing ECAP method or cold rolling [9,31]. Bednarczyk et al. obtained $510 \%$ of elongation at strain rate $1 \times 10^{-4} \mathrm{~s}^{-1}$ in the $\mathrm{Zn}-0.5 \mathrm{Cu}$ alloy [9], meanwhile Mostaed et al. at the same rate observed $470 \%$ of elongation at the same rate for the cold-rolled $\mathrm{Zn}-1 \mathrm{Cu}$ alloy. While the effect itself is well established as determined by a series of static tensile tests at different strain rates, the clear source of the mechanisms behind the superplasticity effect observed in Cu-bearing Zn alloys is not been unambiguously concluded. The authors of the abovementioned works were more focused on characterizing the initial microstructure prior to the tensile tests with different strain rates, which was strongly justified since grain size is one of the key factors affecting the superplastic effect [32]. Bednarczyk et al. concluded that superplastic effect was generally caused by grain boundary sliding (GBS). This mechanism was not considered in our investigations due to texture analysis. GBS should cause texture randomization or at least some intensity weakening [33] and, in our studies, with the increasing reduction rate, the texture intensity increased as well. The later work reported by Mostaed et al. provides an explanation that the superplastic effect of the cold-rolled $\mathrm{Zn}-1 \mathrm{Cu}$ alloy is possible due to the phase boundary sliding, and the in-creased volume fraction of the $\varepsilon$-phases resulted in more sites for the activation of $\mathrm{Zn} / \mathrm{CuZn}_{4}$ boundary sliding rather than $\mathrm{Zn} / \mathrm{Zn}$ glides, because cold rolling provoked strain-induced precipitations. Our results also proved strain-induced precipitations and with the increasing reduction rate, a pronounced number of new precipitates were observed. However, our other results also revealed that $\mathrm{CuZn}_{4}$ precipitates tend to strengthen the material and they are an obstacle to dislocation movement. Firstly, it can be proved by the fact that the $\mathrm{Zn}-5 \mathrm{Cu}$ alloy possessed lower plasticity than the $\mathrm{Zn}-1 \mathrm{Cu}$ alloy. Secondly, a more detailed microstructural investigation in the nanoscale done by TEM observation of the $\mathrm{Zn}-1 \mathrm{Cu}$ alloy after the tensile test revealed numerous interactions of dislocations with the $\mathrm{CuZn}_{4}$ phase. The interactions between dislocations and second phases were observed during TEM investigations of the $\mathrm{Zn}-1 \mathrm{Cu}$ alloy cold-rolled with $90 \%$ of the reduction after the uniaxial tensile test. The pile-up of dislocations on the $\varepsilon$-phase as well as dislocation bowing around particle were found and presented in Figure 13. However, our uniaxial tensile tests were conducted with only one strain rate, while in $[9,31]$ the authors performed more comprehensive mechanical tests covering the strain rate range of $10^{-5} \div 10^{0} \mathrm{~s}^{-1}$, thus the possibility of other mechanisms controlling superplastic effect cannot be excluded. Nevertheless, our investigation proved the substantial contribution of DRX in achieving remarkable plasticity and thus should not be neglected in future work concerning the superplasticity of $\mathrm{Zn}$-based materials.
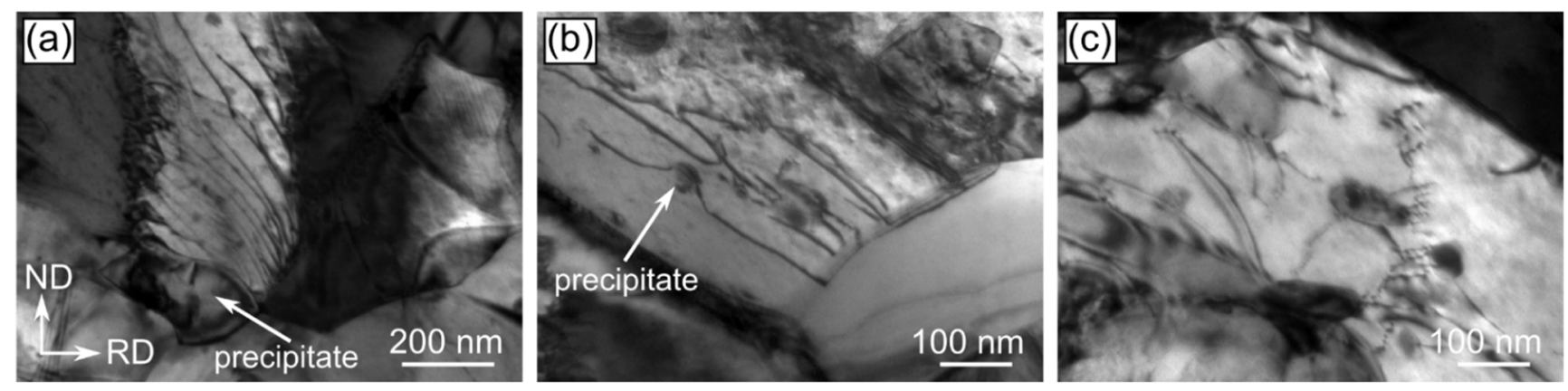

Figure 13. TEM/BF microstructure of the cold-rolled $\mathrm{Zn}-1 \mathrm{Cu}$ alloy with $90 \%$ of reduction after uniaxial tensile test: pile-up of dislocations around the $\mathrm{CuZn}_{4}$ precipitate (a), bowing of dislocation around the $\mathrm{CuZn}_{4}(\mathbf{b})$ and dislocations annihilation into sub-grain around the $\mathrm{CuZn}_{4}(\mathrm{c})$.

\section{Conclusions}

The presented results revealed the origin for superior plasticity and general improvement in the formability of $\mathrm{Zn}$ alloys by studying microstructural evolution. The dynamic recrystallization process can be crucial in microstructural formation and, hence, it governs 
the mechanical properties. The observed continuous dynamic recrystallization process is not only responsible for grain refinement of $\mathrm{Zn}-\mathrm{Cu}$ alloys but also significantly contributes to achieving remarkable plasticity and even the superplastic effect for the $\mathrm{Zn}-1 \mathrm{Cu}$ alloy cold-rolled with the reduction of $90 \%$. This was possible due to the heterogeneous microstructure. In coarse grains, dislocation movement is still possible, although due to dynamic recovery, dislocations annihilate and form sub-grains. The sub-grain boundaries eventually rotate into HAGBs due to the CDRX mechanism. Next, some grains can grow again due to static recrystallization and the process in some specific conditions can happen continuously.

Author Contributions: Conceptualization, A.J. and M.B.; methodology, A.J.; formal analysis, A.J., Ł.M., M.B. and R.C.; investigation, Ł.M., R.C., M.W., K.J. and Ł.R.; writing-original draft preparation, A.J. and Ł.M.; writing - review and editing, M.B., D.W., M.W. and K.S.; visualization, A.J. and D.W.; supervision, K.S.; funding acquisition, A.J. All authors have read and agreed to the published version of the manuscript.

Funding: This research was funded by National Science Center Poland, grant number UMO2017/25/N/ST8/02870.

Institutional Review Board Statement: Not applicable.

Informed Consent Statement: Not applicable.

Data Availability Statement: The data presented in this study are available in repository of corresponding author.

Acknowledgments: Authors are grateful to A. Tarasek for her assistance in cold rolling and uniaxial tensile test experiments and to D. Kalita for his assistance in sample preparation for uniaxial tensile test experiments.

Conflicts of Interest: The authors declare no conflict of interest. The funders had no role in the design of the study; in the collection, analyses, or interpretation of data; in the writing of the manuscript, or in the decision to publish the results.

\section{References}

1. Venezuela, J.; Dargusch, M.S. The influence of alloying and fabrication techniques on the mechanical properties, biodegradability and biocompatibility of zinc: A comprehensive review. Acta Biomater. 2019, 87, 1-40. [CrossRef]

2. Kabir, H.; Munir, K.; Wen, C.; Li, Y. Recent research and progress of biodegradable zinc alloy and composites for biomedical applications: Biomechanical and biocorrosion perspectives. Bioact. Mater. 2021, 6, 836-879. [CrossRef]

3. Levy, G.K.; Goldman, J.; Aghion, E. The prospect of zinc as a structural material for biodegradable implants-A review paper. Metals 2017, 7, 402. [CrossRef]

4. Yang, H.; Jia, B.; Zhang, Z.; Qu, X.; Li, G.; Lin, W.; Zhu, D.; Dai, K.; Zheng, Y. Alloying design of biodegradable zinc as promising bone implants for load-bearing applications. Nat. Comun. 2020, 11, 401. [CrossRef]

5. Bowen, P.K.; Shearier, E.R.; Zhao, S.; Guillory, R.J., II; Zhao, F.; Goldman, J.; Drelich, J.W. Biodegradable Metals for Cadiovascular Stents: From Clinical Concerns to Recent Zn-Alloys. Adv. Healthc. Mater. 2016, 5, 1121-1140. [CrossRef] [PubMed]

6. Kawahara, M. Effects of aluminium on the nervous system and its possible link with neurodegenerative diseases. J. Alzheimers Dis. 2005, 8, 171-182. [CrossRef] [PubMed]

7. Grass, G.; Rensing, C.; Solioz, M. Metallic Copper as an Antimicrobial Surface. Appl. Environ. Microbiol. 2011, 77, 1541-1574. [CrossRef] [PubMed]

8. Znhang, E.; Zhao, X.; Hu, J.; Wang, R.; Fu, S.; Qin, G. Antibacterial metals and alloys for potential biomedical implants. Bioact. Mater. 2021, 6, 2569-2612. [CrossRef]

9. Bednarczyk, W.; Kawałko, J.; Watroba, M.; Bała, P. Achieving room temperature superplasticity in the Zn-0.5Cu alloy processed via equal channel angular pressing. Mater. Sci. Eng. A 2018, 723, 126-133. [CrossRef]

10. Niu, J.; Tang, Z.; Huanh, H.; Pei, J.; Zhang, H.; Yuan, G.; Ding, W. Research on a Zn-Cu alloy as biodegradable material for potential vascular stents application. Mater. Sci. Eng. C 2016, 69, 407-413. [CrossRef]

11. Lin, J.; Tong, X.; Wang, K.; Sji, Z.; Li, Y.; Dargusch, M.; Wen, C. Biodegradable Zn-3Cu and Zn-3Cu-0.2Ti alloys with ultrahigh ductility and antibacterial ability for orthopedic applications. J. Mater. Sci. Technol. 2021, 68, 76-90. [CrossRef]

12. Mosayyebi, A.; Manes, C.; Carugo, D.; Smoani, B.K. Advanes in Ureteral Stent Designe and Materials. Curr. Urol. Rep. 2018, 19, 35. [CrossRef] [PubMed] 
13. Li, P.; Zhang, W.; Dai, J.; Xepapadeas, A.B.; Schweizer, E.; Alexander, D.; Scheideler, L.; Zhou, C.; Zhang, H.; Wan, G.; et al. Investigation of zinc-copper alloys as potential materials for craniomaxillofacial osteosynthesis implants. Mater. Sci. Eng. C 2019, 103, 109826. [CrossRef] [PubMed]

14. Zhou, C.; Li, H.F.; Yin, Y.X.; Shi, Z.Z.; Li, T.; Feng, X.Y.; Zhang, J.W.; Song, C.X.; Cui, X.S.; Xu, K.L.; et al. Long-term in vivo study of biodegradable $\mathrm{Zn}-\mathrm{Cu}$ stent: A 2-year implantation evaluation in porcine coronary artery. Acta Biomater. 2019, 97, 657-670. [CrossRef] [PubMed]

15. Tang, Z.; Niu, J.; Huang, H.; Zhang, H.; Pei, J.; Ou, J.; Yuan, G. Potential biodegradable Zn-Cu binary alloys developed for cardiovascular implant applications. J. Mech. Behav. Biomed. Mater. 2017, 72, 182-191. [CrossRef] [PubMed]

16. Qu, X.; Yang, H.; Jia, B.; Yu, Z.; Zheng, Y.; Dai, K. Biodegradable Zn-Cu alloys show antibacterial activity against MRSA bone infection by inhibiting pathogen adhesion and biofilm formation. Acta Biomater. 2020, 117, 400-417. [CrossRef] [PubMed]

17. Tang, Z.; Huang, H.; Niu, J.; Zhang, L.; Zhang, H.; Pei, J.; Tan, J.; Yuan, G. Design and characterizations of novel biodegradable Zn-Cu-Mg alloys for potential biodegradable implants. Mater. Des. 2017, 117, 84-94. [CrossRef]

18. Wang, Y.N.; Huang, J.C. Texture analysis in hexagonal materials. Mater. Chem. Phys. 2003, 81, 11-26. [CrossRef]

19. Hadadzadeh, A.; Mokdad, F.; Wells, M.A.; Chen, D.L. A new grain orientation spread to analyze the dynamic recrystallization behavior of a cast-homogenized Mg-Zn-Zr alloy using electron backscattered diffraction. Mater. Sci. Eng. A 2018, 709, 285-289. [CrossRef]

20. Shi, Z.Z.; Gao, X.X.; Zhang, H.J.; Liu, X.F.; Li, H.Y.; Zhou, C.; Yin, Y.X.; Wang, L.N. Design biodegradable Zn alloys: Second phases and their significant influence on alloy properties. Bioact. Mater. 2020, 5, 210-218. [CrossRef]

21. Huang, K.; Loge, R.E. A review of dynamic recrystallization phenomena in metallic materials. Mater. Des. 2016, 111, 548-574. [CrossRef]

22. Wątroba, M.; Bednarczyk, W.; Kawałko, J.; Bała, P. Fine-tuning of mechanical properties in a Zn-Ag-Mg alloy via cold plastic deformation process and post-deformation annealing. Bioact. Mater. 2021, 6, 3424-3436. [CrossRef]

23. Jarzębska, A.; Bieda, M.; Maj, Ł.; Chulist, R.; Wojtas, D.; Strag, M.; Sułkowski, B.; Przybysz, S.; Pachla, W.; Sztwiertnia, K. Controlled grain refinement of biodegradable $\mathrm{Zn}-\mathrm{Mg}$ alloy: The effect of magnesium alloying and multi-pass hydrostatic extrusion preceded by hot extrusion. Metall. Mater. Trans. A 2020, 51, 6784-6796. [CrossRef]

24. Bednarczyk, W.; Watroba, M.; Kawałko, J.; Bała, P. Can zinc alloys be strengthened by grain refinement? A critical evaluation of the processing of low-alloyed binary zinc alloys using ECAP. Mater. Sci. Eng. A 2019, 748, 357-366. [CrossRef]

25. Roatta, A.; Leonard, M.; Nicoletti, E.; Singnorelli, J.W. Modeling texture during monotonic loading of Zn-Cu-Ti alloy sheet using the viscoplastic self-consistent polycrystal model. J. Alloys Compd. 2021, 860, 158425. [CrossRef]

26. Leonard, M.; Moussa, C.; Roatta, A.; Seret, A.; Signorelli, J.W. Continuous dynamic recrystallization in a Zn-Cu-Ti sheet subjected to bilinear tensile strain. Mater. Sci. Eng. A 2020, 789, 139689. [CrossRef]

27. Schlosser, F.; Schwindt, C.; Fuster, V.; Tommasi, A.; Signorelli, J.W. Crystallographic Texture Evolution of Zinc Sheet Subjected to Different Strain Paths. Metall. Mater. Trans. A 2017, 48A, 2858. [CrossRef]

28. Watroba, M.; Bednarczyk, W.; Kawałko, J.; Lech, S.; Wieczerzak, K.; Langdon, T.G.; Bała, P. A Novel High-Strength Zn-3Ag-0.5Mg Alloy Processed by Hot Extrusion, Cold Rolling, or High-Pressure Torsion. Metall. Mater. Trans. A 2020, 51, 3335-3348. [CrossRef]

29. Liu, S.; Kent, D.; Zhan, H.; Doan, N.; Dargusch, M.; Wang, G. Dynamic recrystallization of pure zinc during high strin-rate compression at ambient temperature. Mater. Sci. Eng. A 2020, 784, 139325. [CrossRef]

30. Liu, S.; Kent, D.; Zhan, H.; Doan, N.; Wang, C.; Yu, S.; Dargusch, M.; Wang, G. Influence of strain rate and crystallographic orientation on dynamic recrystallization of pure Zn during room-temperature compression. J. Mater. Sci. Technol. 2021, 86, 237-250. [CrossRef]

31. Mostaed, E.; Ardakani, M.S.; Sikora-Jasinska, M.; Drelich, J.W. Precipitation induced room temperature superplasticity in Zn-Cu alloys. Mater. Letter. 2019, 244, 203-206. [CrossRef] [PubMed]

32. Zhao, Y.; Toth, L.S.; Massion, R.; Skrotzki, W. Role of grain boundary sliding in texture evolution for nanoplasticity. Adv. Eng. Mater. 2017, 1700212. [CrossRef]

33. Raja, A.; Jayagnthan, R.; Tiwari, A.; Rakesh, S. Effect of grains size on superplastic deformation of metallic materials. In Aluminium Alloys and Composites, 1st ed.; Cooke, K., Ed.; IntechOpen: Rijeka, Croatia, 2020. [CrossRef] 